3. Estrera AL, Miller CC, Kaneko T, Lee TY, Walkes JC, Kaiser LR, et al. Outcomes of acute type A aortic dissection after previous cardiac surgery. Ann Thorac Surg. 2010;89:1467-74.

4. Hassan M, Carvalho EM, Macedo FI, Gologorsky E, Salerno TA. Paradigm change in the management of patients with acute type A aortic dissection who had prior cardiac surgery. J Card Surg. 2010;25:387-9.
5. Geomez-Moreno S, Sabate M, Jimenez-Quevedo P, Vazquez P, Alfonso F, Hernandez-Antolin R, et al. Iatrogenic dissection of the ascending aorta following heart catheterization: incidence, management, and outcome. EuroIntervention. 2006; 2:197-202.

6. Garg P, Buckley O, Rybicki FJ, Resnic FS. Resolution of iatrogenic aortic dissection illustrated by computed tomography. Circ Cardiovasc Interv. 2009;2:261-3.

\title{
Circumferential intimal tear in type A aortic dissection with intimo-intimal intussusception into left ventricle and left main coronary artery occlusion
}

Sepehr Seyed Lajevardi, MBBS, ${ }^{\mathrm{a}}$ Karan Sian, MBBS, ${ }^{\mathrm{a}}$ Michael Ward, MBBS, PhD, ${ }^{\mathrm{b}}$ and

David Marshman, MBBS, ${ }^{\text {a }}$ Sydney, Australia

Video clip is available online.

Circumferential intimal disruption of the ascending aorta is a rare and potentially lethal occurrence. ${ }^{1}$ The intimal flap can intussuscept into the left ventricular outflow tract, causing significant aortic regurgitation, and may impair coronary perfusion of the coronary arteries (Figure 1). We discuss a case of type A aortic dissection with circumferential intimal tear and intimo-intimal intussusception causing intermittent total left main coronary artery (LMCA) occlusion.

\section{CLINICAL SUMMARY}

A 73-year-old woman who was a nursing home resident was found lying on the floor amnesic to events. She was taken to the emergency department with a symptom of central chest pain. Her medical history was significant for longstanding untreated hypertension, heavy smoking, and mild Alzheimer's dementia. On examination, the patient had a heart rate of 50 beats/min and a systolic blood pressure of $70 \mathrm{~mm} \mathrm{Hg}$. Investigations showed intermittent, widespread ST depression and T-wave inversion on

\footnotetext{
From the Departments of Cardiothoracic Surgery ${ }^{\mathrm{a}}$ and Cardiology, ${ }^{\mathrm{b}}$ Royal North Shore Hospital, University of Sydney, Sydney, Australia.

Disclosures: Authors have nothing to disclose with regard to commercial support.

Received for publication March 29, 2012; accepted for publication May 7, 2012; available ahead of print June 7, 2012.

Address for reprints: Sepehr Seyed Lajevardi, MBBS, Department of Cardiothoracic Surgery, Royal North Shore Hospital, Pacific Highway, St Leonards NSW 2065, Sydney, Australia (E-mail: sepehrlaj@gmail.com).

J Thorac Cardiovasc Surg 2012;144:e21-3 0022-5223/\$36.00

Crown Copyright $\odot 2012$ Published by Elsevier Inc. on behalf of The American Association for Thoracic Surgery

http://dx.doi.org/10.1016/j.jtcvs.2012.05.010
}

electrocardiogram, and an increased troponin $\mathrm{T}$ level of $93 \mathrm{ng} / \mathrm{L}$ (normal, $<14 \mathrm{ng} / \mathrm{L}$ ) on blood test results.

With an initial diagnosis of acute coronary syndrome, urgent coronary angiography was performed (Figure 2, A, and Video $1, A$ and $B$ ). There appeared to be complete proximal occlusion of the LMCA. However, the appearance of "late ghosting" of the LMCA and preserved left ventricular function was not consistent with a total LMCA occlusion. On aortography, there was evidence of extensive Stanford type A aortic dissection, and left ventriculography revealed diastolic prolapse of the aortic intima through the left ventricular outflow tract causing severe aortic regurgitation. The appearance of complete occlusion of the LMCA was thought to be due to intermittent occlusion of the left coronary ostium by the intussuscepting dissection flap or placement of the angiographic catheter in the inner intima (intussusceptum).

The patient was taken urgently to the operating room, and the intraoperative transesophageal echocardiography (TEE) showed circumferential dissection of the ascending aorta, with the cylinder-shaped intimal flap intussuscepting back into the left ventricle causing severe aortic regurgitation (Figure 2, B, and Video 2, $A$ and $B)$. TEE also showed mild left ventricular hypertrophy and mild inferior wall hypokinesis. Aortotomy revealed a circumferential intimal tear originating approximately $3 \mathrm{~cm}$ from the sinotubular junction with the false lumen extending to the aortic root. Valve leaflets and coronary ostia had a normal appearance. The patient underwent successful aortic valve resuspension with replacement of the affected ascending aorta. Postoperative computed tomography aortography revealed that the dissection extended down to the iliac vessels involving multiple aortic branches (Figure 3), which was managed conservatively. She progressed well postoperatively and was discharged to respite care. 


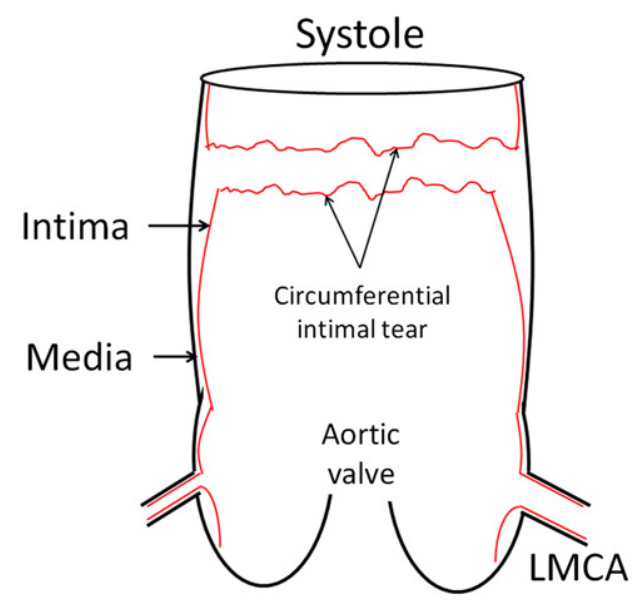

A

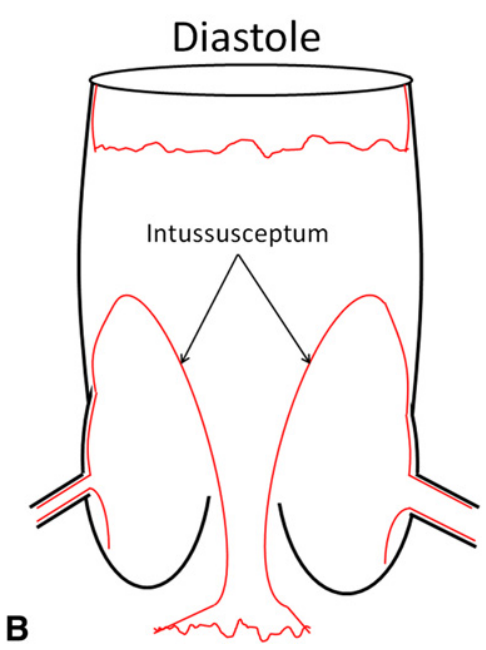

FIGURE 1. A, Circumferential intimal tear of ascending aorta. In systole, the proximal flap is approximately in line with the distal flap. B, Intimo-intimal intussusception in diastole. The intussusceptum prolapses back through the aortic valve, causing aortic regurgitation and occlusion of the coronary artery ostia. LMCA, Left main coronary artery.

\section{DISCUSSION}

In acute aortic dissection, there is usually a transverse intimal tear that rarely exceeds more than half the circumference of the aorta. ${ }^{1}$ There have been only a few reported cases of circumferential intimal tear in the literature in which the cylinder-shaped dissected intima telescoped back into the proximal intima. ${ }^{1-3}$ This is referred to as an "intimo-intimal intussusception." Given the potential for acute coronary occlusion, as well as severe acute aortic regurgitation, this is one of the most potentially fatal forms of type A aortic dissection. It can result in a rapid hemodynamic deterioration and requires urgent surgical management. ${ }^{3}$
Most case reports highlight the difficulty in making a timely diagnosis of this condition. In this instance, the presenting symptoms were suggestive of acute coronary syndrome, and urgent coronary angiography revealed the aortic dissection and diastolic prolapse of the proximal intimal flap into the left ventricle, which was confirmed on intraoperative TEE and direct visualization once the aorta was incised. TEE has been suggested as the best diagnostic modality, which could be performed intraoperatively when aortic dissection is suspected. ${ }^{2,4}$

There have also been reported cases of patent coronary arteries not visualized on coronary angiography because of the flap suffocation of coronary ostia..$^{5}$ In such cases, coronary
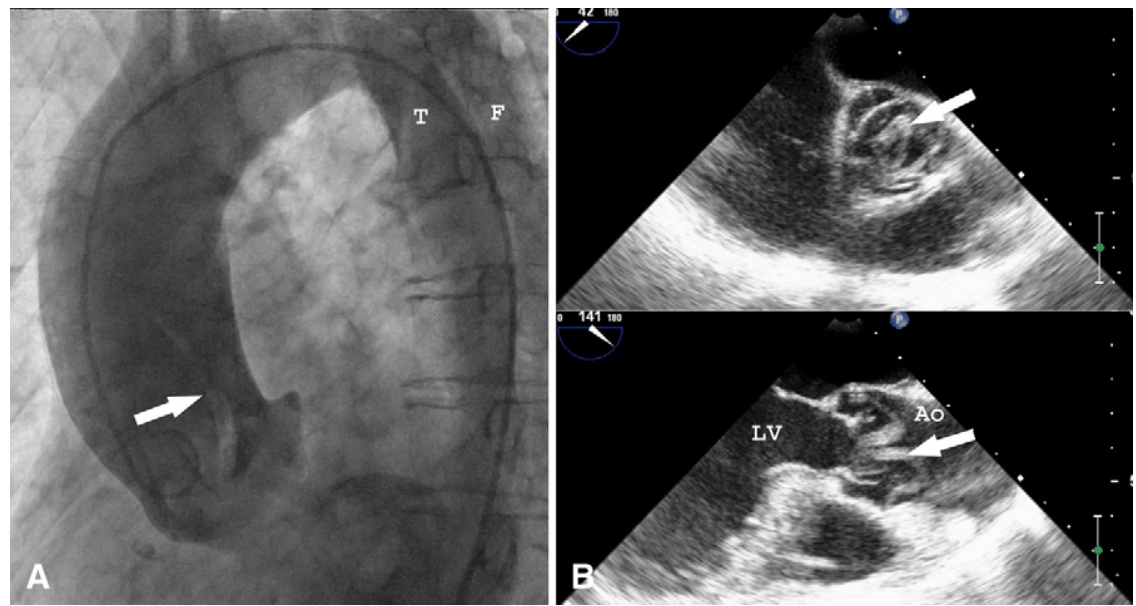

FIGURE 2. A, Angiography showing aortic dissection extending to the descending thoracic aorta with the true and false lumens. Appearance of total LMCA occlusion and prolapse of intimal flap (arrow) through the aortic valve. B, top, TEE showing intimo-intimal intussusception in the proximal aorta (arrow indicating intussusceptum). B, bottom, TEE view of left ventricular outflow tract and proximal aorta. The intussusceptum (arrow) prolapses through the aortic valve. Ao, Aorta; $L V$, left ventricle; $F$, false; $T$, true. 

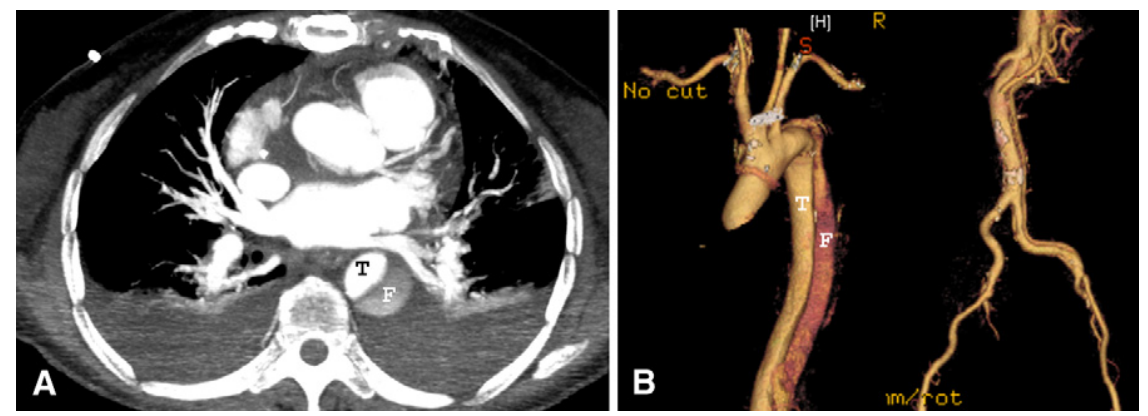

FIGURE 3. Axial (A) and 3-dimensional (B) postoperative CT angiography showing the dissection extending down the aorta to the level of iliac vessels and true and false lumens. $F$, False; $T$, true.

perfusion might be maintained as the flap returns back to the aorta in systole. This was most likely the case in our patient because there was "late ghosting" of the left coronary system and no decrease in left ventricular function despite the appearance of total occlusion of the LMCA, and coronary artery bypass graft was not warranted.

\section{CONCLUSIONS}

In cases of acute aortic dissection, the potential for a circumferential intimal tear needs to be considered because intimo-intimal intussusception, although rare, is a serious complication of aortic dissection. Coronary angiography may indicate complete coronary artery occlusion that may be due to the intussuscepting flap and will resolve once the aortic defect has been repaired. Intraoperative
TEE is the best investigative modality before definitive management with operative repair.

\section{References}

1. Yavuz S, Elhan K, Eris C, Tugrul Goncu M. Intimo-intimal intussusception: a rare clinical form of aortic dissection. Eur J Cardiothorac Surg. 2003;23:850-1; author reply 851

2. Chow JL, Mariano ER, Liang D. Transesophageal echocardiography assessment of severe aortic regurgitation in type a aortic dissection caused by a prolapsed circumferential intimal flap. J Cardiothorac Vasc Anesth. 2007;21:85-7.

3. Yamabi H, Imanaka K, Sato H, Matsuoka T. Extremely localized aortic dissection and intussusception of the intimal flap into the left ventricle. Ann Thorac Cardiovasc Surg. 2011;17:431-3.

4. Yavuz S, Eris C, Turk T. Re: Severe aortic regurgitation caused by a prolapsed circumferential intimal flap in acute type A aortic dissection: role of intraoperative transesophageal echocardiography? J Cardiothorac Vasc Anesth. 2008;22:941.

5. Massetti M, Neri E, Babatasi G, et al. Flap suffocation: an uncommon mechanism of coronary malperfusion in acute type A dissection. J Thorac Cardiovasc Surg. 2003;125:1548-50.

\title{
Pulsatile biventricular assist device and an absent mitral valve
}

\author{
Igor Gosev, MD, Stephanie L. Mick, MD, Gregory S. Couper, MD, and Prem S. Shekar, MD, Boston, Mass
}

We report the case of a 23-year-old African American woman with a history of discoid lupus erythematosus who presented with severe mitral valve insufficiency and preserved left ventricular function. The initial attempt at repair was unsuccessful, and she received a bioprosthetic valve replacement. Sequential valve dehiscence resulted in 2 subsequent reoperations and repeat valve replacements with

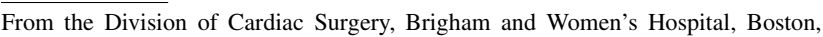
Mass.

Disclosures: Authors have nothing to disclose with regard to commercial support. Received for publication April 9, 2012; accepted for publication May 7, 2012.

Address for reprints: Igor Gosev, MD, Division of Cardiac Surgery, Brigham and Women's Hospital, 15 Francis St, 02115, Boston, MA (E-mail: igosev@ partners.org).

J Thorac Cardiovasc Surg 2012;144:e23-5

$0022-5223 / \$ 36.00$

Copyright (c) 2012 by The American Association for Thoracic Surgery

http://dx.doi.org/10.1016/j.jtcvs.2012.05.011
}

a bioprosthesis and mechanical prosthesis, respectively. She underwent testing for endocarditis that was found to be negative on both occasions, but she did receive empiric endocarditis therapy on both occasions.

Two weeks after the third operation, florid biventricular failure from a recurrent valve dehiscence developed in the patient. There was no impairment of the mechanical leaflet motion. Emergency surgery was performed.

At surgery, it was found that the mitral valve prosthesis had completely dehisced from a nearly nonexistent annulus. Mitral valve replacement was deemed impossible, so the mechanical valve was explanted and a pulsatile biventricular assist device (BIVAD, Thoratec Corporation, Pleasanton, Calif) was placed for biventricular dysfunction.

The patient's early postoperative period was complicated by hypoxic respiratory failure and inability to be weaned from respiratory support. Chest x-rays showed florid 